\title{
PATERNIDADE, FAMÍLIA E CRIMINALIDADE: UMA ARQUEOLOGIA ENTRE O DIREITO E A PSICOLOGIA
} PATERNIDAD, FAMILIA Y CRIMINALIDAD: UNA ARQUEOLOGÍA ENTRE EL
DERECHO Y LA PSICOLOGÍA
PATERNITY, FAMILY AND CRIME: A ARCHAEOLOGY BETWEEN LAW
AND PSYCHOLOGY

Lisandra Espíndula Moreira

Universidade Federal de Alagoas, Maceió/AL, Brasil

Maria Juracy Filgueiras Toneli

Universidade Federal de Santa Catarina, Florianópolis/SC, Brasil

\begin{abstract}
RESUMO
Este artigo tem como objetivo analisar arqueologicamente enunciados que articulam paternidade, família e criminalidade, tendo como corpus de pesquisa documentos da jurisprudência de Tribunais de Justiça. Problematizamos movimentos enunciativos que articulam Paternidade e Criminalidade: paternidade na matriz heterossexual - o pai se produz na diferenciação da mãe; paternidade como isonomia; as classificações que posicionam diferentes pais. Ampliando a análise investigamos também os enunciados que acionam o pai como um dos elementos da família, sem diferenciá-lo. Em relação às famílias, os enunciados se movimentam, normatizando formas de ser família - possibilitando a intervenção e destituição, ou preservando-a como bem social. A família figura nos documentos como elemento importante e determinante para a análise do criminoso, com deslocamento das explicações para a criminalidade do determinismo biológico para o determinismo familiar.
\end{abstract}

Palavras-chave: paternidade; criminalidade; família; práticas sociais.

\section{RESUMEN}

El presente artículo se propone analizar la arqueología de la relación existente entre la paternidad, la familia y la delincuencia. Los materiales investigados fueron los documentos de la jurisprudencia de los Tribunales de Justicia. Proponemos algunos movimientos que articulan Paternidad y el Delito: la paternidad en la matriz heterosexual - el padre se produce en la diferenciación de la madre; paternidad como la igualdad; clasificaciones que posicionan diferentes padres. Extendiendo el análisis también investigó las afirmaciones que desencadenan el padre como un elemento de la familia, pero sin lo diferencia. En cuanto a las familias, los enunciados se mueven, la estandarización de las formas de ser de la familia - que permite la intervención, o preservarla como un bien social. La familia aparece en los documentos como importante y decisivo para el análisis del desplazamiento de explicaciones para el delito de determinismo biológico para el elemento de determinismo familia.

Palabras clave: paternidad; criminalidad; família; prácticas sociales

\begin{abstract}
This article discuss the relationship between paternity, family and crime, by analyze of the discourse in legal documents. It takes, as the research corpus, documents archived at the case law of the Courts of Justice in southern Brazil's states. From these documents we question statement movements that support links between Fatherhood and Crime. There are numerous movements in regard to paternity: paternity in the heterosexual matrix; paternity as equality; classifications for different fathers. Extending the analysis, it researches the statements that trigger the father as one of the family, no differentiates it. Regarding households, moving statements standardizing ways of being family. The family appear in the documents as an important and crucial to the analysis of criminal.
\end{abstract}

Keywords: paternity; crime. Family; social practices. 
Esta pesquisa emerge do questionamento sobre as articulações entre paternidade e criminalidade. Em especial, do incômodo diante da forte associação entre ausência paterna e criminalidade. Não tivemos a intenção de provar verdadeira ou falsa essa associação, mas lapidar as articulações entre paternidade e criminalidade, arrancando lascas que as fazem parecer tão óbvias e naturais. O intuito foi evidenciar as marcas históricas que carregam como herança e colocar em questão jogos entre Psicologia e Direito, evidenciando as enunciações jurídicas que acionam e articulam paternidade e criminalidade. Este estudo se inscreve na perspectiva arqueológica de Foucault (2005), tomando como objeto de análise os enunciados que se apresentam em documentos jurídicos. A saber, o corpus de pesquisa foi composto por acórdãos pesquisados na jurisprudência de tribunais de justiça.

$\mathrm{Na}$ revisão de literatura, percorremos alguns enunciados científicos que permitem colocar o pai como questão e objeto de estudo. Analisar as condições e a emergência da paternidade reside na premissa de que não estamos falando de um objeto anterior a essa aparição: "O objeto não espera nos limbos a ordem que vai liberá-lo e permitir-lhe que se encarne em uma visível... mas existe sob as condições positivas de um feixe complexo de relações" (Foucault, 2005, p.50). Conhecer o discurso científico torna visíveis os regimes de verdade que constituem essa fabricação de pais e paternidades. Nesse percurso, percebemos as marcas das várias metamorfoses sociais, econômicas, científicas, tecnológicas que tornaram possíveis as condições para um maior envolvimento dos homens na vida familiar, em especial no cuidado com os filhos.

A revisão privilegiou discursos científicos que estabelecem ou problematizam a relação causal entre paternidade e efeitos para o filho, e os materiais serão citados à medida que se relacionam com os eixos analíticos. Não colocamos em questão se o pai ocupa espaço na formação ou na constituição da criança. O que procuramos questionar é a forma como essa argumentação se constrói. A associação entre o exercício da paternidade e a conduta do filho se torna possível através do investimento de uma teoria do desenvolvimento. As teorias do desenvolvimento (principalmente nas disciplinas psi e na medicina) deram "visibilidade à criança, descrevendo suas habilidades e comportamentos, as etapas do seu desenvolvimento e as posições que pais e mães precisavam assumir para o sucesso do mesmo, constituindo, assim, modos (corretos, normais) de ser criança, mãe e pai” (Hennigen, 2010, p.174).

\section{Corpus de pesquisa: produção de arquivo}

Esta não é uma pesquisa que conta com um guia metodológico que sabe desde o início o caminho a percorrer, como se todos os caminhos estivessem mapeados previamente. Tomando as reflexões metodológicas como ferramentas de pesquisa, em especial a arqueologia, desenhamos alguns mapas. O rigor metodológico neste abrir caminhos está exatamente na descrição cuidadosa e na análise crítica e detalhada de cada encruzilhada que se atravessou.

Propomos construir uma análise da articulação entre paternidade e criminalidade a partir da jurisprudência, que está atravessada por diversos enunciados, aproximando-se da arqueologia. Arqueologia não como a busca de um começo ou de uma exploração geológica, mas como "o tema geral de uma descrição que interroga o já dito no nível de sua existência; da função enunciativa que nele se exerce, da formação discursiva a que pertence, do sistema geral de arquivo de que faz parte" (Foucault, 2005, p.149).

Partimos de alguns princípios inspiradas em Foucault (2005), de sorte a elaborar uma analítica que: (a) não se propõe interpretativa, como se buscasse um discurso mais oculto; dirige-se ao discurso na qualidade de monumento; (b) não busca a transição contínua, mas quer "definir os discursos em sua especificidade; mostrar em que sentido o jogo de regras que utilizam é irredutível a qualquer outro" (p.157); (c) não é ordenada pela figura da obra, pois busca descrever práticas discursivas que podem atravessar obras individuais, comentando-as na íntegra ou em parte; (d) não se propõe a reconstituição do pensamento ou do desejo no momento em que os discursos foram proferidos; a arqueologia se constitui na "descrição sistemática de um discurso-objeto" (p.158).

Tomar a articulação entre paternidade e criminalidade a partir dos enunciados é tomar cuidado para escapar da busca por um correlato. Não há nesta pesquisa o intuito de verificar se essa articulação existe, autenticando a veracidade de uma proposição causal entre ausência paterna e criminalidade. $\mathrm{O}$ enunciado não está ligado ao correlato, mas sim a um:

referencial que não é constituído de "coisas", de "fatos", de "realidades", ou se "seres", mas de leis de possibilidade, de regras de existência para os objetos que aí se encontram nomeados ou descritos, para as relações que aí se encontram afirmadas ou negadas. O referencial do enunciado forma o lugar, a condição, o campo de emergência, a instância de diferenciação dos indivíduos ou dos objetos, dos estados de coisas e das relações que são postas em jogo pelo próprio 
enunciado; define as possibilidades de aparecimento e de delimitação do que dá à frase seu sentido, à proposição seu valor de verdade. (Foucault, 2005, p.103)

Essas condições de análise dos enunciados, como funções enunciativas, provocam um deslocamento no modo de analisar. Não se busca atribuir "sentidos" aos enunciados, mas relacioná-los com um campo de objetos. Abrem-se posições subjetivas possíveis ao invés de definir aos enunciados um sujeito/autor. Em vez de limitá-los, posiciona-se-os num domínio de coordenação e coexistência.

Inspiradas em Butler (citada por Prins \& Meijer, 2002), indagamos "sobre como certos tipos de discurso produzem efeitos ontológicos ou operam através da circulação de movimentos ontológicos" (p.159). A estratégia para alcançar esse objetivo está em permanecer no contexto dos próprios discursos, uma vez que "não existe nenhuma forma de contestar esses tipos de gramáticas a não ser habitá-las de maneira que produzam nelas uma grande dissonância, que 'digam' exatamente aquilo que a própria gramática deveria impedir" (p. 159).

A metodologia privilegia a análise dos discursos, entendendo-os como "conjunto regular de fatos linguísticos em determinado nível e polêmicos e estratégicos em outro" (Foucault, 2005, p. 9). Entende-se o termo discurso não apenas como uma fala ou escrita, mas como o modo do que está dito estabelece relações de poder e de saber. Foucault vai mostrar a ligação do discurso com as questões de desejo e poder. O discurso "não é simplesmente aquilo que traduz as lutas ou os sistemas de dominação, mas aquilo porque, pelo que se luta" (Foucault, 2006, p. 10). Nesse caso, escrever sobre as articulações entre Psicologia e Direito a partir de seus discursos é, além de produzir essas articulações, apropriar-se desse espaço, criando-o permanentemente nessa escrita e análise.

Adentramos o corpus da pesquisa - a jurisprudência. No Direito brasileiro, a compilação dos acórdãos produzidos nos tribunais configura o que se chama de Jurisprudência, ou seja, as reiteradas decisões dos Tribunais. "Derivado do latim jurisprudentia, de jus (Direito, ciência do Direito) e prudentia (sabedoria), entende-se literalmente que é a ciência do Direito vista com sabedoria. Assim é que se entende a jurisprudência como sábia interpretação e aplicação das leis" (Silva, 2009, p. 806). A Jurisprudência mostra-se campo fértil de análise por seu caráter histórico - permite analisar como têm sido utilizadas algumas argumentações - e por seu caráter futuro - quando poderá servir como precedente para legitimar decisões vindouras. Nesse aspecto, verificase a sua potencialidade normalizadora.

\begin{abstract}
A jurisprudência apresenta-se, portanto, como um aparato jurídico que $\ldots$ opera como dispositivo de poder, cujos efeitos incidem diretamente no cotidiano familiar, na vida de homens e mulheres nestes novos arranjos sociais contemporâneos. Opera por meio de um conjunto de regras constitutivas das práticas discursivas que normalizam modos de vida, atividades familiares, profissionais, de consumo e de sociabilidade. (Perucchi, 2008, p. 62)
\end{abstract}

Não é a decisão em si que configurou o objeto de análise, mas as enunciações que conformam embasamento e justificativa de determinadas decisões no que acionam, movimentam, inventam, transformam os enunciados que articulam paternidade e criminalidade. A pesquisa foi inteiramente realizada pelo acesso virtual aos sites oficiais de cada tribunal. Os tribunais pesquisados foram: Tribunais de Justiça da região Sul do Brasil (Rio Grande do Sul: TJRS, Santa Catarina: TJSC e Paraná: TJPR), o Tribunal Regional Federal (TRF4 - refere-se à região Sul do Brasil), Supremo Tribunal Federal (STF) e Superior Tribunal de Justiça (STJ). Ao acessar cada site, a busca era feita no campo da jurisprudência, com o cruzamento de alguns termos, como palavras-chaves: paternidade e criminalidade. Além desses dois termos usados, utilizamos algumas variações e aproximações, impulsionadas pela revisão bibliográfica. Em relação à paternidade, usamos também pai, família e genitor. Quanto à criminalidade, utilizamos também o termo delinquência. Além disso, buscamos uma associação de termos que é bem conhecida e escutada pela Psicologia: família desestruturada, que aponta para uma determinada expectativa de estrutura familiar e de funções para cada um de seus membros.

As variações de termos buscaram abarcar palavras que são de uso comum no Direito e no cotidiano, apesar de não serem escolhidas como conceitos norteadores da presente tese por possuírem algumas limitações - carregam marcas que a própria pesquisa se propõe questionar. É o caso da palavra genitor; bastante usada no corpus analisado: ela limita o conceito de paternidade/pai àquele homem que teve a função biológica da concepção.

Esta pesquisa teve como panorama as informações organizadas na Tabela 1, que mostra o desafio de trabalhar com esses materiais tão numerosos. A tabela apresenta os resultados da busca, diferenciando o tribunal que foi investigado e o cruzamento de termos utilizados. 
Tabela 1. Quantidade de documentos acessados em cada tribunal a partir dos descritores

\begin{tabular}{lccccccccccccc}
\hline \multicolumn{1}{c}{ Tribunais } & \multicolumn{2}{c}{ RS } & \multicolumn{2}{c}{ SC } & PR & TRF4 & STJ & STF & Total \\
\hline \multicolumn{1}{c}{$\begin{array}{l}\text { Descritores } \\
\text { Total }\end{array}$} & Corpus & Total & Corpus & Total & Corpus & Total & Corpus & Total & Corpus & Total & Corpus \\
$\begin{array}{l}\text { Criminalidade } \\
\text { Paternidade }\end{array}$ & 0 & 0 & 8 & 8 & 0 & 0 & 2 & 2 & 0 & 0 & 0 & 0 & 10 \\
$\begin{array}{l}\text { Criminalidade } \\
\text { Família }\end{array}$ & 52 & 10 & 3 & 3 & 20 & 10 & 95 & 10 & 3 & 3 & 8 & 8 & 44 \\
$\begin{array}{l}\text { Criminalidade } \\
\text { Pai }\end{array}$ & 8 & 7 & 297 & 10 & 1 & 1 & 84 & 10 & 3 & 3 & 11 & 10 & 41 \\
$\begin{array}{l}\text { Criminalidade } \\
\text { Genitor }\end{array}$ & 0 & 0 & 26 & 8 & 2 & 2 & 7 & 7 & 1 & 1 & 0 & 0 & 18 \\
$\begin{array}{l}\text { Delinquência } \\
\text { Paternidade }\end{array}$ & 0 & 0 & 4 & 4 & 0 & 0 & 1 & 1 & 0 & 0 & 0 & 0 \\
$\begin{array}{l}\text { Delinquência } \\
\text { Pai }\end{array}$ & 1 & 1 & 66 & 10 & 2 & 2 & 25 & 10 & 14 & 10 & 0 & 0 & 33 \\
$\begin{array}{l}\text { Delinquência } \\
\text { Família }\end{array}$ & 2 & 2 & 107 & 10 & 5 & 5 & 28 & 10 & 4 & 4 & 0 & 0 \\
$\begin{array}{l}\text { Família } \\
\text { desestruturada }\end{array}$ & 14 & 8 & 10 & 10 & 4 & 4 & 1 & 1 & 3 & 3 & 0 & 0 \\
\hline
\end{tabular}

Todos os materiais foram lidos e analisados a partir da figura do arquivo, não apenas como um conjunto de documentos guardados numa determinada instância, mas entendendo que "O arquivo é o que define o modo de atualidade do enunciado-coisa, é o sistema de seu funcionamento" (Foucault, 2005, p.147). Portanto, toma-se o arquivo na descrição de seu funcionamento, tendo como trabalho paralelo a análise dos enunciados. É pensar nas coisas ditas, descrevê-las, analisá-las na medida em que expressam um sistema de discursividade e as possibilidades e impossibilidades enunciativas que ele conduz. Tomar os materiais de análise como arquivo permite que se pense certo sistema de enunciados presente na prática jurídica. "O arquivo é de início, a lei do que pode ser dito, o sistema que rege o aparecimento dos enunciados como acontecimentos singulares" (Foucault, 2005, p.147).

Interrogamos, então, os textos analisados e, por que não, o próprio texto que escrevemos, com as questões inspiradas em Foucault:

Quem pode falar? De que lugar fala? Que relações estão em jogo entre a pessoa que fala e aquilo que é objetificado no relato? Ou seja, quem são os sujeitos de enunciação que se constituem para que aquele relato seja inteligível e legítimo? (Nardi, 2010, p. 127)

\section{Articulações entre paternidade e criminalidade}

O enunciado que foi o ponto de partida dessa pesquisa - ausência paterna como causadora de criminalidade - não surge como uma fórmula mágica nos materiais, o que surgem são movimentos de enunciados que, de diversas formas, articulam essas duas questões (criminalidade e paternidade) e, com isso, evidenciam lutas de forças, jogos de saber/poder que vão se mesclar para que surjam as enunciações que fundamentam as sentenças lidas. Em relação à paternidade, ressaltamos três movimentos enunciativos: (a) a paternidade heteronormativa em demanda de abandono afetivo, (b) a paternidade como isonomia e (c) as classificações de paternidade.

A paternidade heteronormativa surge de diferentes formas, mas toma um contorno especial num acórdão de abandono afetivo. Trata-se de uma Apelação Cível ${ }^{1}$ (TJSC, 2007), interposta pela mãe.

O Direito entra na família, acompanhado do saber psi, para prescrever, determinar e fiscalizar tarefas e funções específicas para os agentes que ali se encontram. Eis que se constrói, nesse documento, um lugar de pai.

A ausência das funções paternas já se apresenta hoje, inclusive, como um fenômeno social alarmante e provavelmente é o que tem gerado as péssimas 
consequências conhecidas por todos nós, como o aumento da delinquência juvenil, menores de rua e na rua, etc. Esta ausência paterna e o declínio do paterviril está acima da questão da estratificação social. É um fenômeno e consequência das transformações sociais iniciadas com a revolução feminista, a partir da redivisão sexual do trabalho e a consequente queda do patriarcalismo. (TJSC, 2007)

A categoria "pai" está sendo construída, potencializada e/ou regulada pelas mesmas estruturas de poder através das quais busca legitimação ou através das quais é solicitada a prestar contas. Na produção e ocultação de sujeitos políticos, os pressupostos retiram o caráter histórico das categorias identitárias, assim como invisibilizam as diferenças e "intersecções com modalidades raciais, classistas, étnicas, sexuais e regionais de identidades discursivamente constituídas" (Butler, 2003,p. 20).A interferência das transformações sociais aparece como um processo que deturparia a função "natural" e "a-histórica" do pai no exercício da autoridade. As enunciações estabelecem a primazia desta problemática - ausência paterna - em relação a alguns outros marcadores sociais (estratificação social, abandono material). $\mathrm{O}$ enunciado exclui ou minimiza os efeitos de outras relações de poder nos fenômenos colocados em questão (aumento da delinquência juvenil, menores de rua e na rua, dentre outros).

A definição da paternidade como categoria explicativa é possível no acionamento de sua diferenciação em relação à maternidade. Caso contrário, seria parentalidade ou, de forma mais ampla, o papel da família. Problematizar essa construção binária é colocar em questão os limites das especificidades do que se direciona para homens e mulheres, para pais e mães, para o masculino e o feminino. Em que medida a categoria "pai" só alcança estabilidade e coerência no contexto da matriz heterossexual? Matriz heterossexual ou heteronorma ou heterossexualidade compulsória são modos de explicitar uma operação permanente, mas ao mesmo tempo invisibilizada, que exige unidade entre sexo, gênero e desejo (homem, masculino) de forma oposicional à outra unidade de sexo, gênero e desejo (mulher, feminino).

Haja vista a imprescindibilidade da presença paterna na existência do indivíduo e, tendo em conta os efeitos negativos da ausência do pai na vida do filho, é inegável que o abandono afetivo constitui ato atentatório à dignidade da pessoa humana em processo de desenvolvimento e hábil a gerar dano moral. (TJSC, 2007)

Aparentalidade,constituídanaheterossexualidade compulsória, diferencia o exercício a partir de sujeitos posicionados como pais ou mães. Em decorrência, a paternidade e a maternidade são fabricadas conforme um arranjo social prévio e a-histórico.

"Pater viril" marca a impossibilidade de pensar a "função paterna" para além da presença ou referência a um corpo masculino. Um corpo masculino dotado de pênis, ativo, heterossexual, potente. $\mathrm{O}$ apelo à construção de um "pater viril" assegura o exercício da paternidade a um determinado sexo, remete esse sexo a um corpo que seria naturalmente diferenciado anatomicamente e posicionado num determinado polo dessa binaridade.

A articulação entre paternidade e criminalidade não se fixa nesse argumento. Os enunciados circulam, e o segundo movimento enunciativo que descrevemos refere-se à forma como a paternidade pode estar associada à ideia de isonomia. Num Reexame Necessário Cível do Tribunal Regional Federal (TRF4, 2010), discute-se uma revisão de sentença para permissão da licença paternidade de 90 dias para servidor que adotou sozinho uma criança.

A questão da criminalidade surge não diretamente como ausência de paternidade, mas como a ausência de vínculo familiar em geral, que seria então um argumento para o incentivo à adoção. A enunciação minimiza o fato de ser um homem o adotante, dando maior ênfase à grandeza do ato de adotar, pois "vivemos num país que convive ainda com elevado número de crianças em total abandono e às margens da criminalidade" (TRF4, 2010). Estar incluído numa família, mesmo com a flexibilização das noções de família, seria sempre melhor do que estar fora dela.

Cabe pensar nas condições de possibilidade da infância circular como sujeito a ser protegido, acionando a mobilização de instâncias públicas e familiares. Arantes (1999) aponta "como marco histórico normativo, no plano internacional, a Convenção das Nações Unidas sobre os Direitos da Criança (1989) e, no plano nacional, a Constituição Federal (Brasil, 1988) e o Estatuto da Criança e do Adolescente (Brasil, 1990)" (p.1). Além disso, interessa pensar no uso da criança (seu bem-estar e interesse) para o enunciado: "Ao tentar circunscrever o 'interesse da criança' entram em cena valores morais, significados de masculino e feminino que definem as atribuições maternas e paternas e consequentemente influenciam as decisões judiciais" (Unbehaum Ridenti, 1998, p. 178).

Ao se referir ao princípio da isonomia para argumentação em prol da licença para o pai, a decisão aproxima-se de uma subversão da lógica de dicotomia sexual: "Obstacularizar o direito do servidor implicaria manifesta ofensa ao princípio constitucional 
da isonomia" (TRF4, 2010). Não se apela para a diferença de funções ou de tarefas no caso do cuidado exercido pelo pai ou pela mãe, mas para os direitos que os iguala, ou pelo menos deveria igualá-los diante da lei. Aqui o pai não está em "luta" com a mãe, situação em que se poderiam examinar as diferenças entre eles. Pelo contrário, à figura do pai cuidador se contrapõe o descuidado, a institucionalização da criança em abrigos ou em escolas de educação infantil ou cuidados alternativos.

Ampliando esses enunciados, descrevemos a produção de posições paternas (pai ausente, pai desconhecido, pai biológico, pai presente) em categorias que não estão dadas de antemão. Para pensar esse terceiro movimento enunciativo, recorremos a um documento que julga o pedido de um pai biológico que, no momento do nascimento do filho, não se encontrava presente e que não se conforma com a entrega da criança para adoção (TJSC, 1995).

Diante de tal situação, teria sido o infante dado para adoção... o comportamento omissivo do pai biológico na oportunidade do nascimento... deixando para agir somente dez meses após o evento, revela, indiscutivelmente, um quê de irresponsabilidade, a qual, a estas alturas, constitui-se em óbice intransponível para reverter a situação. (TJSC, 1995)

Passamos sem escalas de um pai desconhecido para um pai ausente. A decisão não atende ao pedido do pai e mantém a criança no lar adotivo, com base na permissão unilateral da adoção pela mãe. Um detalhe chama a atenção: "a condição financeira estável do casal adotante, consignando, em última análise, a possibilidade de a criança desenvolver-se em um ambiente harmônico e bem estruturado, o que não parece existir no âmbito de sua família natural" (TJSC, 1995). Oposição perigosa entre ambiente harmônico e bem estruturado (condição financeira estável) x família natural (laço biológico). Eis uma forma de articular paternidade e criminalidade bastante elucidativa marcada pela causalidade: "o indivíduo fará sua opção pelo caminho do bem ou do mal, sendo o ambiente familiar determinante para tal escolha" (TJSC, 1995). A familiaridade com esse argumento nos permite visibilizar alguns aspectos e suspeitar que a criminalidade, outrora explicada através de um determinismo biológico, passa a ter a possibilidade de explicação num determinismo familiar.

A presença paterna tão aclamada para o desenvolvimento adequado da criança pressupõe um pai suficientemente adaptado, disciplinado. Quando o sujeito escapa a essas premissas, há necessidade de inversão desse investimento, decidindo-se afastar compulsoriamente o pai. Esse movimento enunciativo de produção e categorização de pais se apresenta também numa Apelação Cível do Tribunal de Justiça de Santa Catarina. O documento relata uma decisão em que o pai, privado de liberdade, recorre à justiça para manter o poder familiar de suas filhas menores: "Em suas razões de apelação, o pai demonstra interesse em permanecer com a guarda das menores, asseverando não restar provado nos autos sua ausência na criação e sustento das filhas" (TJSC, 2009).

O poder familiar que poderia ser entendido como um direito do pai vai ser questionado à medida que ele implica um tensionamento nos direitos das crianças. O pedido do pai foi negado. Toneli, Araújo, Amaral e Silva (2011) explicitam a tensão entre direitos e deveres "quando se trata de justificar a participação/ inclusão dos homens na arena dos direitos reprodutivos e, em especial, na paternidade" (p. 128).

Dessa tensão entre os direitos, deveres e proibições relativas ao exercício da paternidade, brotam também tensões em relação às formas de avaliar se esse vínculo está ou não se exercendo de forma adequada, o que, algumas vezes, poderá determinar se é caso de direito, dever ou proibição. A paternidade precisa ser objetivada, verificada, comprovada, e isso acaba por minimizar questões mais subjetivas.

Alegar que possui amor, sentimentos de carinho sem que haja uma real contrapartida de responsabilidade, sem que haja um verdadeiro ato de vínculo emocional não basta. A criança precisa de adultos, cuidadores responsáveis, implicados com o processo de crescimento de seus filhos, implicados com a construção subjetiva do sujeito com o devido respeito que eles merecem... Ela merece e terá do Judiciário a resposta que precisa, necessária à garantia de seus direitos fundamentais. (TJSC, 2009)

Movimentam-se enunciados, mas mantém-se em alguns a associação causal entre ausência paterna e criminalidade. A ânsia de descobrir as causas e identificar a criminalidade não é recente. "Para alguns teóricos, o tipo físico do criminoso era tão previsível que seria possível delimitá-lo de forma objetiva" (Schwarcz, 1993, p. 166).

Em final do século XIX e início do século $\mathrm{XX}$ se estabelece uma correlação entre debilidade e delinquência. "A frenologia foi associada à degenerescência e à eugenia, e ganhou novas confirmações com o modelo determinista de Lombroso (1835-1909) para quem a criminalidade era um fato biológico inato, cujos sinais viriam cunhados na face do criminoso"(Lobo, 2008, p. 59). A causalidade, nesse período, se estabelecia com as marcas corporais que cada criminoso carregava, muitas vezes coincidindo 
com diferenças estabelecidas na classificação das diferentes raças.

Propomos pensar que a associação causal entre ausência paterna e criminalidade poderia representar um refinamento desse argumento explicativo sobre a criminalidade. Antes as causas eram buscadas e encontradas (ou produzidas) no corpo e, agora, as causas são buscadas e encontradas (ou produzidas) na constituição psíquica do sujeito - que se estabeleceria como reflexo da constituição familiar e do exercício das funções de cada membro da família, inclusive do pai. A implicação dessa transição pode ser uma autorização para intervenções na família, determinando modos adequados de cuidar e criar filhos adaptados. Essa é a produtividade do enunciado que se multiplica em diferentes práticas sociais.

\section{Alargando o enunciado: do pai à família}

Para prosseguir na análise dos movimentos enunciativos importantes na articulação de paternidade e criminalidade, operamos um alargamento de algumas noções e propomos problematizar questões relacionadas à família. A paternidade se torna dizível de determinada forma numa dada concepção de família. A família pode ser compreendida como uma peça chave para a análise das formas de governo das populações. Entender a família como um instrumento privilegiado para exercício do controle sobre os sujeitos e, portanto, como forma mesma de constituição desses sujeitos, possibilita, na sequência, pensar na posição ocupada pela paternidade nessa engrenagem. Problematizamos ainda a paternidade, mas agora como uma peça na incessante produção da engrenagem chamada "família".

Dos enunciados que constroem articulações entre família e criminalidade, relatamos dois movimentos enunciativos que se mostraram fortes na medida em que atualizam outros enunciados: (a) a família que nada tem de família; e (b) a família como a instância que define o que o sujeito é.

A discussão dos limites do que pode ou não ser considerado uma família surge fortemente numa Apelação Cível (TJSC, 2011) que busca revisar a decisão de destituição do poder familiar. Nesse documento, a família surge como um conjunto de pessoas, listadas e analisadas conforme parâmetros de saúde e adaptação social. Um retrato de família, nomeado como "situação familiar desestruturada", não resulta de uma desestrutura pela ausência de algum membro (pai, mãe, filhos), mas de uma classificação dos membros em categorias desqualificadas socialmente para o exercício de funções de cuidado - alcoólatras, dependentes químicos, diagnóstico de transtorno mental, prostituição, dentre outros.

A família, e o pai, é uma de suas peças, que se diferencia das outras famílias transforma-se em alvo de intervenções realizadas por equipe legitimada pela instância estatal, que nos usos de seus saberes e poderes atende, cuida, orienta, fiscaliza, controla, e, nesse caso, denuncia as práticas familiares consideradas inadequadas. Fartos são os relatos dessas intervenções e prescrições, dispositivos de correção familiar: "realizados diversos estudos sociais, informativos sociais e relatórios, tudo no intuito de acompanhar a situação e tentar adequar e estruturar a família" (TJSC, 2011). Nos tentáculos contemporâneos do biopoder que abraçam o corpo dessa família e os corpos de cada um de seus membros, encontra-se não O poder, como uma espada apontada a sujeitar verticalmente, forçar, reprimir, ordenar modos de ser. "Um modo de agir sobre um ou vários sujeitos ativos, e o quanto eles agem ou são suscetíveis de agir" (Foucault, 1995, p. 243). Nas interpelações direcionadas a essa família, as instâncias não agem pela família, mas travam um embate para que as ações dessa família se conformem a certo rol de possibilidades de ser pai e de ser mãe autorizado e legitimado.

A família resiste, insiste em formas de funcionar que escapam às prescrições de adequação social, psicológica, médica, jurídica. "Embora tenha havido certos períodos de melhora, como na internação dos pais em clínicas de reabilitação, logo depois ambos reincidiram nos mesmos erros" (TJSC, 2011). Essas práticas se aproximam ao que Scheinvar e Lemos (2012) problematizam na atuação dos Conselhos Tutelares, que oferecem "assistência em pequenas doses visando à moralização, fazendo acionar, simultaneamente, no complexo tutelar, norma e moral" (p. 79). Esses enunciados mostram o quanto é difícil se contrapor à legislação que prioriza a família como instância de proteção, associando esse privilégio à vinculação biológica.

Também não podemos nos furtar a pensar que há um atravessamento de classe que se coloca nesse cenário. Seriam as mesmas intervenções, caso a família tivesse uma condição financeira maior? Responderíamos negativamente a essa questão, pensando na tendência de criminalização da pobreza no Brasil, que carrega marcas "das teorias racistas, do eugenismo, da teoria da degenerescência e do movimento higienista" (Coimbra, 2006, p. 3). Nesse aspecto, as intervenções ou fiscalizações da conduta da família pobre serviriam mais para "comprovar" sua natureza perigosa do que para amparar práticas 
de parentalidade tidas como mais saudáveis. É nessa articulação entre pobreza e periculosidade que se justificam práticas mais efetivas em prol da criança pobre.

devemos tomar uma decisão que pode nos parecer muito radical que é retirar desta família as crianças ... e ainda o recém nascido de $\mathrm{V}$. que ainda tem chance de ser educado dentro dos padrões que tem direito, será que uma destituição do poder familiar seria mais agressivo do que permanecer dentro desta família que nada tem de família e permitir que eles também daqui a pouco tempo já estejam se drogando, bebendo e se prostituindo também. (TJSC, 2011, grifo nosso)

A argumentação estabelece uma divisão entre famílias, a família que seria verdadeiramente família, e essa família que é menos família que o necessário. Essa família rompe com as possibilidades de inteligibilidade que certo modelo de família concede. A norma familiar se impõe sutil e cotidianamente através de orientações, prescrições, indicações, produzindo diferenciações entre famílias e também diferenciando cada um de seus membros (pai, mãe, filhos etc.), não conseguindo, mesmo assim, capturar e disciplinar suficientemente essa família e acaba por ser necessária a intervenção jurídica.

Os enunciados de família também se movimentam. Saindo desses retratos de família "que nada tem de família", encontramos documentos que acionam de outra forma a questão familiar e colocam a família como instância determinante na constituição do sujeito, fator de mensuração da personalidade e da periculosidade. A família ("é pai de família", TJPR, 2007) pode ser vista como um fator positivo na avaliação do sujeito que está sendo julgado. "O paciente reúne condições pessoais favoráveis: profissão definida, mantém sua empresa, é pai de família, tem residência fixa e disponibilizou seu passaporte para demonstrar que não tem interesse em fuga" (TJPR, 2007).

No caso de julgamentos dos que cometeram algum crime, as questões familiares são realçadas, lançando luzes sobre o que se pressupõe de sua identidade. Há uma articulação entre família e personalidade na qual se analisam os laços familiares como forma de mensurar uma determinada personalidade. Mas isso nos aponta também para uma ânsia de conseguir capturar essa personalidade, e sua tendência ao crime, que faz com que o crime deixe de ser um ato e passe a ser uma identidade, um atributo do sujeito que permeará outras ações possíveis. A família circula como instância que constitui elemento a ser analisado para diferentes aspectos, em especial: culpabilidade, conduta social e personalidade nesse jogo do estabelecimento da pena.
A questão da personalidade, que junto com a conduta social influencia o cálculo da pena, relacionase diretamente com a questão da subjetividade, articulando Direito e Psicologia, lançando luzes para a questão da família como forma de compreender a constituição desse sujeito, encarcerado na sua personalidade. A subjetividade, os modos de ser, de viver, de se posicionar nas situações cotidianas vão sendo mensurados em questões bem práticas de outros delitos (antecedentes criminais) e da sua conduta/ constituição/estabilidade familiar.

Não mais o ato, mas o hábito será objeto de análise para a pena. Abre-se "espaço para uma aplicação da lei modulada segundo 'circunstâncias atenuantes' - ou agravantes - ligadas às condutas e virtualidades do indivíduo em julgamento" (Prado Filho, 2012, p. 108). Esse movimento, a partir do século XIX, evidencia que o Direito Penal vai abrindo mão da punição como "defesa da sociedade para punir de forma mais individualizada o infrator e corrigir o indivíduo desviante da norma" (Prado Filho, 2012, p.108).

No vazio deixado pelo deslocamento do cálculo da pena, que não fica mais restrito ao delito, abre-se uma articulação fértil com o saber psi - chamado ao palco do tribunal para conceder também seu veredito sobre a subjetividade daquele que está no banco dos réus e que concederá à família um lugar de destaque dentro da história de cada sujeito. Com base nesses elementos, a dose da pena será calculada nos mínimos gramas, efetivamente como um remédio, no qual "o duro ofício de punir vê-se assim alterado para o belo ofício de curar" (Foucault, 2001, p. 29). A personalidade vai delimitando um aprisionamento do sujeito, elo entre a sua biografia, sua conduta e suas tendências futuras. Nessa ideia de personalidade se produz a noção de periculosidade. Esse aparato, na sua face terapêutica ou judiciária, não visa centralmente a doença ou o crime, mas o perigo.

$\mathrm{Na}$ ânsia de julgar, prever, prevenir, atribuir uma tendência de ação, tira-se o foco apenas da ocorrência delituosa para ampliar o olhar, borrando os limites do julgamento que invade os modos de ser do sujeito, sua profissão, sua biografia, suas experiências familiares. No limite, essas são as condições que tornam possível a construção da articulação entre paternidade e criminalidade. A associação entre ausência paterna e criminalidade seria a herança desses movimentos que atribuem uma personalidade ao sujeito, entendendo a família como uma das causas de personalidades com tendência criminosa.

Herança das figuras anormais, a articulação entre ausência paterna e criminalidade provém, 
inicialmente, da ânsia de explicação da conduta desviante (seja o anormal, o louco, o deficiente, o delinquente). Essa ânsia, que ao longo do tempo foi sofrendo metamorfoses, sem abrir mão totalmente das roupagens anteriores, foi deixando de se fixar no corpo para buscar explicações na produção de uma interioridade (tida como personalidade) que poderia ser capturada por meio da investigação da história do sujeito. E é na história do sujeito que a família reina quase que isoladamente. Da família, investigam-se sua configuração, suas relações internas, o exercício dos papéis, o cumprimento das funções num script bastante definido e no qual, em se tratando de criminalidade, o pai é figura de destaque. Essa análise permite problematizar por que o enunciado da ausência paterna como determinante da criminalidade funciona tão bem em determinados contextos sociais.

\section{Considerações}

Escrever nem uma coisa Nem outra - A fim de dizer todas $\mathrm{Ou}$, pelo menos, nenhumas. Assim, Ao poeta faz bem Desexplicar - Tanto quanto escurecer acende os vaga-lumes. (Barros, 2004)

O objetivo deste artigo foi evidenciar as marcas históricas que a articulação paternidade, família e criminalidade carrega como herança, analisando documentos jurídicos, empreendimento operacionalizado por meio da análise dos enunciados, no que eles evidenciam sobre a regularidade, as descontinuidades e rupturas dos discursos, além das condições de possibilidade, suas emergências e proveniências.

Em relação à paternidade, os enunciados se movimentam desde a paternidade como produtora e efeito da matriz heterossexual - a paternidade na sua diferenciação com a maternidade, passando pela paternidade como isonomia, até chegar às classificações diversas que hierarquizam as práticas paternas. No primeiro movimento, problematizar a construção binária é colocar em questão os limites das especificidades do que se direciona para homens e mulheres, para pais e mães, para o masculino e feminino. $\mathrm{O}$ desdobramento da diferenciação entre "pai" e "mãe" se fundamenta na descrição minuciosa dos limites no exercício do cuidado ou "afeto" esperado de cada um. Prescrição fabricada conforme um arranjo social prévio e a-histórico, onde ao pai estaria delegado o ponto de partida do sujeito, representante da lei. Já a transformação da paternidade em parentalidade ocorre quando a demanda foi por cuidados especificamente, fazendo falar a isonomia como princípio que permitiria ao sujeito pai trabalhador os mesmos direitos de licença para cuidar dos filhos. De forma mais emblemática os documentos acionam classificações em relação à paternidade, diagnosticando modos de ser pai e lançando previsões sobre os efeitos dessa prática ou ausência sobre a constituição daquele filho.

Para compreender como esses enunciados se tornam possíveis, adentramos alguns movimentos enunciativos que acionam o pai de forma menos específica, tomando-o como mais um elemento da família. A família funciona como espaço denso das formas de normalização da existência. Àquelas que não correspondem adequadamente aos parâmetros traçados, são designadas práticas de atenção, cuidado e controle.

Num último elemento de análise, cabe pensar na família utilizada para entender e prever a personalidade. Aqui, chegamos à tese do determinismo familiar de forma mais explícita. Compreendemos que a articulação entre paternidade e criminalidade tem suas condições possibilitadas por movimentos que normatizam as relações internas à família, mas também por transformações na própria lógica criminológica, em especial, a queda do determinismo biológico ao longo do século XX.

Fica no horizonte a importância da pesquisa na interface do Direito com a Psicologia e a potência dessa articulação para a compreensão de outras práticas sociais, em especial, alguns desdobramentos dessas questões para as políticas públicas. Leituras contemporâneas de Foucault propõem a judicialização da vida como uma das formas de problematização do presente, tendo em vista a amplitude alcançada pelas práticas jurídicas. Nascimento e Scheinvar (2012) questionam o uso do judiciário como palco primordial para a solução de todos os problemas. É necessário colocar em questão a "naturalização das práticas judiciárias como o maior veículo para estabelecer as relações cotidianas, sejam elas de ordem formalinstitucional, como as de trabalho, administrativas e penais, sejam elas de ordem afetiva, como as conjugais ou parentais" (Nascimento \& Scheinvar, 2012, p. 1).

Diante de tantas explicações e determinações em que a criminalidade, a família e a paternidade figuram como objetos e se produzem mutuamente, esta pesquisa não quis ser mais uma explicação. $\mathrm{O}$ que buscamos como objetivo principal deste estudo foi problematizar arqueologicamente as articulações entre paternidade, família e criminalidade. Nesse processo, problematizamos essas explicações que fixam o problema da criminalidade na família, mais especificamente no pai; questionamos a criminalidade como "o" problema; deslocamos a posição da família como origem e causa da criminalidade; colocamos 
em questão a paternidade como origem da autoridade. Movimentos necessários para "desexplicar" a articulação entre paternidade e criminalidade, no sentido de fugir ao fácil acionamento explicativo da determinação familiar e, quiçá, acionar outros focos de luminosidade, na compreensão histórica da produção desses enunciados. "Desexplicar", como propõe Manuel de Barros: "Tanto quanto escurecer acende os vaga-lumes" (Barros, 2004).

\section{Nota}

Apelação, termo originado do latim appelatio, designa um dos recursos que a pessoa prejudicada pela sentença pode utilizar, a fim de que, subindo a ação para superior instância, pronuncie uma nova sentença, confirmando ou modificando a anterior (Silva, 2000).

\section{Referências}

Arantes, E. M. (1999). De "criança infeliz" a "menor irregular" - Vicissitudes na arte de governar a infância. In A. M. JacóVilela, F. Jabur, \& H. B. C. Rodrigues, H. B. C. (Orgs.), Cliopsyché: histórias da psicologia no Brasil. Rio de Janeiro: UERJ, NAPE. Acesso em 20 de outubro, 2013, em http:// www.cliopsyche.uerj.br/livros/clio1/decriancainfeliz.htm

Barros, M. (2004). Retrato quase apagado em que se pode ver perfeitamente nada. In M. Barros, O Guardador de Águas (4 ed., pp. 55-65) Rio de Janeiro: Record.

Butler, J. (2003). Problemas de gênero: feminismo e subversão da identidade (R. Aguiar, Trad.). Rio de Janeiro: Civilização Brasileira.

Coimbra, C. (2006, outubro). Direitos Humanos e criminalização da pobreza. Trabalho apresentado em Mesa Redonda: Direitos Humanos e Criminalização da Pobreza no I Seminário Internacional de Direitos Humanos, Violência e Pobreza: a situação de crianças e adolescentes na América Latina. Acesso em 27 de maio, 2014, em http://www.slab. uff.br/images/Aqruivos/textos sti/Cec\% $\% 3 \%$ ADlia $\% 20$ Coimbra/texto54.pdf

Foucault, M. (1995). Microfisica do poder (R. Machado, Trad.). Rio de Janeiro: Graal.

Foucault, M. (2001). Os anormais: curso no Collège de France (1974-1975) (E. Brandão, Trad.). São Paulo: Martins Fontes.

Foucault, M. (2005). A arqueologia do saber (7 $7^{\mathrm{a}} \mathrm{ed}$.). Rio de Janeiro: Forense Universitária.

Foucault, M. (2006). A ordem do discurso: Aula Inaugural no Collège de France, pronunciada em 2 de dezembro de 1970 (L. A. Sampaio, Trad., 13a ed.). São Paulo: Edições Loyola.

Hennigen, I. (2010). Especialistas advertem: o pai é importante para o desenvolvimento infantil. Fractal: Revista de Psicologia, 22(1), 169-184.

Lobo, L. F. (2008). Os infames da história: pobres, escravos e deficientes no Brasil. Rio de Janeiro: Lamparina.

Nardi, H. C. (2010). Da norma e da lei: psicologia e direito no campo da diversidade sexual. In R. S. Silveira (Org.), Direito e psicologia: o desafio da interdisciplinaridade (pp. 123144). Porto Alegre: Ed. UniRitter.

Nascimento, M. L. \& Scheinvar, E. (2012). Editorial. Psicologia $\&$ Sociedade, 24(n.spe), 01-01.
Perucchi, J. (2008). "Mater semper certa est pater nunquam". $O$ discurso jurídico como dispositivo de produção de paternidades. Tese de Doutorado, Universidade Federal de Santa Catarina, Florianópolis.

Prado Filho, K. (2012). Uma breve genealogia das práticas jurídicas no Ocidente. Psicologia \& Sociedade, 24(n. spe.), 104-111.

Prins, B. \& I. C. Meijer, I. C. (2002). Como os corpos se tornam matéria: entrevista com Judith Butler. Revista Estudos Feministas, 10(1), 155-167.

Scheinvar, E. \& Lemos, F. C. S. (2012). Os direitos da criança e do adolescente: o caminho da judicialização. Universidade e Sociedade: Revista ANDES-SN, ano 22, 50, 72-81. Acesso em 20 de outubro, 2013, em http://portal.andes.org.br/ imprensa/publicacoes/imp-pub-1891461678.pdf

Schwarcz, L. M. (1993). O espetáculo das raças: cientistas, instituições e questão racial no Brasil 1870-1930. São Paulo: Companhia das Letras.

Silva, P. (2009). Vocabulário Jurídico (28 ed., versão atualizada por N. Slaibi Filho \& G. Carvalho). Rio de Janeiro: Editora Forense.

Tribunal de Justiça do Paraná - TJPR. (2007). 04113202 Habeas Corpus. Acesso em 14 de abril, 2014, em http://tj-pr.jusbrasil.com.br/jurisprudencia/6255445/ habeas-corpus-crime-hc-4113202-pr-0411320-2/inteiroteor-12382152

Tribunal de Justiça de Santa Catarina - TJSC. (1995). 48.038 Apelação Cível. Acesso em 13 de abril, 2014, em http://tjsc.jusbrasil.com.br/jurisprudencia/4844263/apelacao-civelac-798646/inteiro-teor-11401822

Tribunal de Justiça de Santa Catarina - TJSC. (2007). 2006.015053-0 Apelação. Acesso em 13 de abril, 2014, em http://tj-sc.jusbrasil.com.br/jurisprudencia/6521648/ apelacao-civel-ac-150530-sc-2006015053-0/inteiroteor-12625918

Tribunal de Justiça de Santa Catarina - TJSC. (2009). 2009.034644-6 Apelação Cível. Acesso em 13 de abril, 2014, em http://tj-sc.jusbrasil.com.br/jurisprudencia/6853394/ apelacao-estatuto-da-crianca-e-do-adolescente-apl-346446sc-2009034644-6/inteiro-teor-12675984

Tribunal de Justiça de Santa Catarina - TJSC. (2011). 2011.036034-0 Apelação Cível. Acesso em 14 de abril, 2014, em http://tj-sc.jusbrasil.com.br/jurisprudencia/20095558/ apelacao-civel-ac-360340-sc-2011036034-0/inteiroteor-20095559

Toneli, M. J. F., Araujo, S. A., Amaral, M. S., \& Silva, F. L. S. (2011). Exercícios e atribuições sociais da paternidade: pequeno balanço de uma década de pesquisa. In M. J. F. Toneli, B. Medrado, Z. A. Trindade, \& J. Lyra (Orgs.), O pai está esperando? Políticas públicas de saúde para a gravidez na adolescência (pp. 125-148). Ilha de Santa Catarina: Editora Mulheres.

Tribunal Regional da Quarta Região - TRF4. (2010). 001916779.2009.404.7100/RS Reexame Necessário Cível. Acesso em 13 de abril, 2014, em http://www2.trf4.gov.br/trf4/ processos/visualizar_documento_gedpro.php?local=trf4\&d 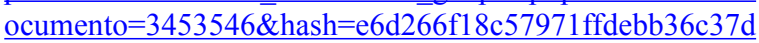 $\underline{3 \mathrm{ff} 90}$

Unbehaum Ridenti, S. G. (1998) A desigualdade de gênero nas relações parentais: o exemplo da custódia dos filhos. In M. Arilha, S. G. Unbehaum Ridenti, \& B. Medrado (Orgs.), Homens e masculinidades: outras palavras (pp. 163-184). São Paulo: ECOS/Editora 34. 


\section{Agradecimento}

À Capes, pelo apoio e financiamento - Bolsa de doutorado Capes/DS".

Submissão em: 23/10/2013

Revisão em: 31/03/2014

Aceite em: 20/04/2014

Lisandra Espíndula Moreira é Psicóloga, Mestre em Psicologia Social e Institucional/UFRGS, Doutora em Psicologia/UFSC e docente do curso de Psicologia da Universidade Federal de Alagoas. Endereço: Universidade Federal de Alagoas, Instituto de Psicologia . Campus A. C.
Simões. Av. Lourival M. Mota, s/n. Tabuleiro do Martins. Maceió/AL, Brasil. CEP 57072-970. E-mail: lisandram@ig.com.br

Maria Juracy Filgueiras Toneli é Professora doutora do curso de Psicologia da UFSC e coordenadora do núcleo de pesquisa "Modos de vida, família e relações de gênero" (MARGENS) da UFSC. E-mail: juracy.toneli@gmail.com

\section{Como citar:}

Moreira, L. E. \& Toneli, M. J. F. (2014). Paternidade, família e criminalidade: uma arqueologia entre o Direito e a Psicologia. Psicologia \& Sociedade, 26(n. spe.), 36-46. 